Article

\title{
Bicycle and Car Share Schemes as Inclusive Modes of Travel? A Socio-Spatial Analysis in Glasgow, UK
}

\author{
Julie Clark and Angela Curl * \\ Urban Studies, University of Glasgow, Glasgow, G12 8RS, UK; E-Mails: julie.clark@glasgow.ac.uk (J.C.), \\ angela.curl@canterbury.ac.nz (A.C.) \\ * Corresponding author
}

Submitted: 14 November 2015 | Accepted: 5 February 2016 | Published: 7 June 2016

\begin{abstract}
Public bicycle and car sharing schemes have proliferated in recent years and are increasingly part of the urban transport landscape. Shared transport options have the potential to support social inclusion by improving accessibility: these initiatives could remove some of the barriers to car ownership or bicycle usage such as upfront costs, maintenance and storage. However, the existing evidence base indicates that, in reality, users are most likely to be white, male and middle class. This paper argues that there is a need to consider the social inclusivity of sharing schemes and to develop appropriate evaluation frameworks accordingly. We therefore open by considering ways in which shared transport schemes might be inclusive or not, using a framework developed from accessibility planning. In the second part of the paper, we use the case study of Glasgow in Scotland to undertake a spatial equity analysis of such schemes. We examine how well they serve different population groups across the city, using the locations of bicycle stations and car club parking spaces in Glasgow, comparing and contrasting bike and car. An apparent failure to deliver benefits across the demographic spectrum raises important questions about the socially inclusive nature of public investment in similar schemes.
\end{abstract}

\section{Keywords}

bicycle-sharing system; car-share; Glasgow; inclusive; modes of travel; shared transport; social inclusion; spatial analysis

\section{Issue}

This article is part of the issue "Transport Policy and Social Inclusion", edited by Miriam Ricci, Graham Parkhurst and Juliet Jain (University of the West of England, UK).

(C) 2016 by the authors; licensee Cogitatio (Lisbon, Portugal). This article is licensed under a Creative Commons Attribution 4.0 International License (CC BY).

\section{Introduction}

Public bicycle sharing schemes and car clubs have proliferated in recent years and are increasingly part of the urban transport landscape (Enoch \& Taylor, 2006; Fishman, Washington, \& Haworth, 2013). There are car clubs in over 1,100 cities worldwide (Shaheen, Martin, Cohen, \& Finson, 2012). Similarly, bicycle share schemes have grown both globally and in the UK: there are now nearly 900 bicycle share schemes worldwide (DeMaio \& Meddin, 2015), including 3,000 vehicles in locations across the UK (CarPlus, 2015a). This growth in shared transport schemes is underpinned by considerable policy interest. From an urban transport manage- ment perspective, shared transport has the potential to reduce congestion and alleviate pressure on parking (Shaheen, Cohen, \& Martin, 2010). Considered at a strategic level, these schemes can be seen as a means of encouraging modal shift towards more sustainableand healthier-modes of transport (Dowling \& Kent, 2015; Marsden, Mullen, Bache, Bartle, \& Flinders, 2014; Ogilvie \& Goodman, 2012; Parkes, Marsden, Shaheen, \& Cohen, 2013). Within this context, car and bicycle sharing could offer a pathway towards lower levels of car ownership (Kent \& Dowling, 2013). This, in turn, should achieve reduced fuel consumption and lower emissions of greenhouse gases and damaging particulates within the urban environment, simultane- 
ously supporting environmental and health policy agendas.

As well as providing potential health benefits by increasing access to active travel and decreasing levels of pollution, it can be theorised that shared transport options have the scope for supporting social inclusion. In parallel with the growth of the compact city agenda towards the turn of the $21^{\text {st }}$ Century, there was an upsurge of interest in transport disadvantage (DETR, 2000; Sinclair \& Sinclair, 2001; Social Exclusion Unit, 2003). A growing understanding of the recursive relationship between urban form and modal choice shed light on the economic, educational and social disadvantages suffered by those unable to fulfill their mobility needs (Hine \& Mitchell, 2003; Lee \& Murie, 1999; Lucas, 2004; Turner \& Grieco, 2000). Part of the promise of shared transport modes is that they offer a level of mobility which might otherwise be unaffordable, and in doing so, can mitigate financial disadvantage for less affluent members of society (O'Brien, Cheshire, \& Batty, 2014; Shaheen et al., 2012).

Together, policy interest, the growth of shared modes, and the scope for enhancing levels of social inclusion seem a promising combination. The objectives of such schemes can be unclear; furthermore, there is little precedent for the evaluation of schemes against any objectives which might have been set (Ricci, 2015). This paper argues that there is a need to evaluate how socially inclusive transport sharing schemes are and, further, to develop appropriate evaluation frameworks. We open by considering car and bicycle schemes, outlining inherent tensions within transport and social inclusion. Thereafter, we propose a framework of what might constitute inclusivity in shared transport modes. In the next part of the paper, we undertake a spatial equity analysis of the schemes in terms of how well they serve different population groups across the city, using the locations of bicycle stations and car club parking spaces in Glasgow, comparing and contrasting bicycle and car.

\section{Shared Transport and Social Inclusion}

\subsection{Shared Transport: Car and Bicycle Schemes}

Car share schemes, often called car clubs, offer access to a fleet of vehicles without the need to own a car. The defining characteristics of both for- and not-forprofit schemes are that they involve short-term rental, with a range of charging structures adopted by different organisations at different times. Participation in a car club generally requires some form of registration and membership. Participants are then charged on duration of hire, distance travelled or some combination of these (Dowling \& Kent, 2015). Users collect a vehicle from dedicated parking bays. Parking stations tend to be located in either city or neighbourhood centres or beside major employment areas (Dowling \& Kent, 2015). More sophisticated, 'free-floating' schemes can accommodate a one-way trip, with the vehicle returned to another approved parking spot rather than the original parking bay (Firnkorn \& Müller, 2011). Despite struggling in the UK, schemes where people share private vehicles have been particularly successful in the US; nevertheless, these peer-to-peer schemes require both an adequate proportion of car owners who are willing to share and setting agreements that allow a baseline of revenue to be generated (Stephany, 2015).

Evidence suggests that car schemes are predominantly used by employed men, aged 26-49 (Loose, 2010), who are also more likely to be well-educated, business users, and from the higher end of the income spectrum (Rabbitt \& Ghosh, 2013). Compared with other drivers, those using car share schemes are likely to have lower levels of car ownership, take fewer private car trips, drive shorter distances, and exhibit more multi-modal and intermodal behaviours, in particular, holding public transport season tickets and having greater bicycle use (Kent \& Dowling, 2013; Kopp, Gerike, \& Axhausen, 2015; Loose, 2010). Evidence indicates that people who participate in a car share reduce the distance they travel by car by up to $45 \%$, and, furthermore, that up to $55 \%$ will give up their private vehicle, while others abandon plans to purchase a new vehicle (Loose, 2010). As well as having lower levels of car dependency, car sharers generate significantly lower annual CO2 emissions (Rabbitt \& Ghosh, 2013). Although there has been recent growth in the availability and popularity of car clubs, adoption of car sharing is still at relatively low levels (Loose, 2010).

Bicycle sharing involves access to bicycles docked at relatively 'desirable' points. Central locations and ease of access also make this a mode which is particularly appealing for visitors to the city. As with car share, no ownership is required and the schemes cover the cost of storage, maintenance and parking (Shaheen et al., 2012). Bicycle share has evolved from early honour or coin operated systems to more sophisticated electronic docking stations, utilising smart cards and requiring either short-term or annual memberships (Buck et al., 2013). Most recently, some schemes have made a further shift, from registration and membership business models to more casual usage, facilitated by the spread of smart, mobile technology, where anyone with access to a debit card can access a hire bicycle (Lathia, Ahmed, \& Capra, 2012). Although bicycle share has been around for longer than car clubs, cycling remains a minority mode in many urban environments and some commentators consider that Europe is still amidst the adoption process of bike-share systems, with the US lagging behind by a further 5-7 years (Parkes et al., 2013).

While the economic barriers to participation in bicycle share are lower than with car share, there are still significant socio-economic and spatial variations in up- 
take (Pucher, Buehler, \& Seinen, 2011). Bicycle scheme users are predominantly male, of relatively high income and, as with car club members, aged around 2544 (Buck et al., 2013). Women and people from deprived areas are likely to be under-represented (Ogilvie \& Goodman, 2012). Additional to gender, age and income, cultural factors may also be an issue; a Dutch study of urban policy and cycle use has found that immigrants with a different cultural background were less likely to cycle, while US research has also found that bicycle sharers were predominantly white (Buck et al., 2013; Rietveld \& Daniel, 2004). Furthermore, although the proportion of white residents in a neighbourhood was found to be insignificant during research into car share usage in New York, the author theorised that the 'real' car share members were recently arrived young, white residents in gentrifying low-income areas (Kim, 2015).

Bicycle share participants in a major North American study of over 10,000 riders 'overwhelmingly' reported less driving, with concomitant reductions in vehicle kilometers and emissions (Shaheen et al., 2012). Additionally, cycling can be used as a secondary mode, travelling to train stations (Heinen, van Wee, \& Maat, 2010), indicating that schemes can also support the use of public transport.

\subsection{Transport and Social Inclusion}

Recent decades have seen an increase in awareness of the social dimensions of mobility and accessibility (Lucas, van Wee, \& Maat, 2015). However, while the growing field of environmental justice deals with the spatial patterning of amenities, transport exclusion constitutes both a literal and metaphorical disconnect which renders people unable to participate in society (Church, Frost, \& Sullivan, 2000). Welch (2013) contends that the equity impacts of mismatched service needs and distribution are still under-researched. The rise of digital connectivity notwithstanding, physical copresence remains a necessity for multiple aspects of social inclusion. While virtual contact can replace physical mobility, particularly for more affluent members of society, many require to 'go' to work, visit medical services or attend places of education. Likewise, virtual contact might be best considered an enhancement of actually meeting with friends and family, rather than a substitute. For all the heralded 'death of distance', the digital age has, thus far, most favoured those who already have the greatest level of resource (Cairncross, 1997; Kenyon, Rafferty, \& Lyons, 2003).

Many studies of accessibility-related exclusion focus on those without a car, which can, to some extent, be considered an implicit endorsement of the car as a solution to transport-related social exclusion. Access to private transport unquestionably provides benefits; however, the dominance of the car and the wider im- pacts of car ownership give rise to a number of environmental, economic and social concerns (Black, 2003; Goodwin, 1999; Hine \& Mitchell, 2001). Fuel, maintenance, and running a car all generate externalities in terms of emissions covering air, water, noise, and ground pollution (Reid, 1995). Congestion is a stress on infrastructure, drivers, other road users including pedestrians, and business (Grant-Muller \& Laird, 2006). Beyond environmental impacts, injuries and fatalities entail economic and human costs, and traffic creates an uncongenial environment, inimical to everyday exercise and social interaction (Appleyard, 1981). Furthermore, demand for private transport diverts resources from other modes (Pucher \& LeFevre, 1996).

The role of place in disadvantage is a wellestablished feature of social inclusion/ exclusion discourse (Kristensen, 1995). Perhaps the most far-reaching impact of the dominance of the car lies in its effect on land use patterns. Freed from the constraint of following established public transport routes, urban activities become dispersed (Muller, 2004). Additionally, the increasing separation of work and home from social and leisure activities fosters isolation and a polarisation between those possessing and those lacking access to private transport, problematising the status of the private car within the modal mix of transport options.

It has been argued that urban compaction can have positive equity effects, in that dense, mixed use development can increase accessibility and reduce car dependence (Burton, 2001). Preston \& Rajé (2007) identify three criteria as important in identifying the degree of transport-related social exclusion: area mobility (the level of travel in an area as a whole); individual mobility (the level of travel made by particular individuals or groups); and the overall accessibility of the area. Within a relatively dense urban environment, it might be hoped that car and bicycle schemes would mitigate exclusion along all of these dimensions. However, the growth of shared transport schemes has also been associated with the hollowing out of the state, as public provision has been withdrawn in favour of expectations the private sector should have primary responsibility for managing transport (Aldred, 2012). This perspective serves to undermine any easy assumption that shared transport will necessarily support greater social inclusion, in that less affluent members of society will be less able to participate in market-based activities.

Policy levers are crucial in supporting modal shift. Considering car club schemes, there are a number of business models: they might be for-profit, cooperatives or non-profit; they are also sometimes associated with a particular public transport network (Hampshire \& Gaites, 2011). Like car clubs, bicycle share schemes have garnered significant policy support and are generally regarded as an uncontentious intervention because of their perceived social and environmental advantages (Parkes et al., 2013). In some cases, 
when parking spaces are converted from general use to 'car share only', public bodies have levied a charge on car share operators to compensate for lost revenue (Shaheen et al., 2010). However, it has been argued that many schemes can only be economically viable given a particular blend of cultural, economic, political and transport contexts and that policy collaboration and support are necessary for shared transport to flourish (Enoch \& Taylor, 2006; Parkes et al., 2013; Ricci, 2015). Promotion, marketing and provision of parking bays, signage and cycling infrastructure are all means through which policy support for shared transport schemes can be demonstrated (Moore, Rodriguez, Tokuhiro, \& Wang, 2012; Pucher, Dill, \& Handy, 2010). In some schemes, this amounts to a de facto state subsidy of private enterprise for the public good. This can be considered questionable, in that the existing evidence base indicates an apparent failure to deliver benefits across the demographic spectrum, raising important questions about the equity of public investment in similar schemes. We therefore develop a framework of what might constitute inclusivity in shared transport modes. In the second part of the paper, we undertake a spatial equity analysis of the schemes in terms of how well they serve different population groups across the city, using the locations of bicycle stations and car club parking spaces in Glasgow, comparing and contrasting bike and car.

\section{Evaluation Framework for Equity Analysis of Shared Transport Schemes}

This section offers a preliminary evaluation framework for examining shared transport schemes in terms of inclusivity. While each scheme operates under different model of delivery and access, here we conceptualise how such schemes might be inclusive and what factors should be considered in an assessment of inclusivity, before focusing more specifically on the case of Glasgow in later sections. We draw on concepts from accessibility planning and equality impact assessments, discussing these with reference to shared bicycle and car schemes. Accessibility Planning is an approach to inclusive transport, designed to reduce barriers to access and address issues of social exclusion. The Social Exclusion Unit (2003) specifies barriers to accessibility, which we consider in analysing shared transport schemes as potentially inclusive modes of travel. Focusing on bicycle and car club parking stations as destinations in their own right, we evaluate their accessibility in relation to other modes, predominantly walking. Additionally, we consider how shared modes might improve accessibility to other destinations in the city, such as providers of employment, education or healthcare. Equality impact assessments evaluate how the positive and negative impacts of proposed transport schemes are distributed across population sub-groups. We therefore complement the accessibility planning approach by considering the distribution of shared transport facilities across the population.

\subsection{Cost}

The cost of transport is a potential barrier to movement which, on the basis of the relative cost of transport as a proportion of income, impacts unevenly upon lower income households (Hine \& Mitchell, 2001). Car ownership is often used as a proxy for income and lack of car ownership is generally associated with lower income and risk of social exclusion (Goodwin, Hallet, Kenny, \& Stokes, 2012; Hine \& Mitchell, 2001).

High 'entry' costs present one of the key problems associated with private car ownership. This also means that once a vehicle has been purchased, it is usually more economical to use it as the main source of transport, rather than to engage with multiple modes. Within this framework, car ownership can be considered as a threat to sustainability and multi-modality agendas that seek to promote alternative modes of transport. In contrast, car clubs are marketed towards those whose transport needs might be partially or incompletely met by car ownership. These might be people who use cars infrequently, who might give up a car, or decide not to purchase a second car (e.g., City Car Club, 2015a). We posit that they also provide the potential to meet the transport needs of those who cannot afford a private vehicle and associated costs but who may require a car for some journeys, thus also having a role to play in transport justice by improving car-based accessibility. However, even though car clubs might offer a more financially viable means of accessing a car, a driving licence is a prerequisite in taking advantage of the opportunity and it should be remembered that the distribution of licences, as well as car ownership, is patterned by socio-economic status.

Similarly, bicycle schemes may provide a lower cost means of entry for those wishing to cycle, and hence can widen available transport options. Nevertheless, particularly in the UK, cycling is now commonly associated with middle class men in lycra (Daley \& Rissel, in press; Goodman, Green, \& Woodcock, 2014) and is likely to be seen as a mode of choice, rather than the 'necessity' which the car is considered by many (Sloman, 2006). However, although lack of car access due to affordability problems might be widely accepted as a problem of transport equity/justice, it can be forgotten that in deprived communities, a bicycle can also be an appreciable expense, especially for multi-member households (Clark \& Kearns, 2014). Therefore, as noted by Goodman, Green, \& Woodcock (2014), there is some evidence to suggest that bicycle sharing schemes can promote inclusivity by ameliorating the issue of entry cost and normalising cycling. However, as with car 
schemes, shared bicycle schemes usually entail user registration, and can require the use of a credit or debit card for access, as insurance or as a deposit. Similarly, internet access, a smart phone or a bank account can be necessary. While it is possible to find schemes that do not have these requirements, given that geography is a pertinent issue, many people may find access either more difficult or impossible, for practical purposes.

The cost of using shared transport, relative to other alternatives, is therefore a crucial consideration when addressing whether shared transport schemes can be seen as an inclusive mode of transport.

\subsection{Physical Access}

When considering physical access to public transport in the UK, the Disability Discrimination Act imposes duties on transport providers to support transport users who have a disability. These include: wheelchair space; step free access; priority seats; size and height of steps; handrails; colour contrast; and information displays (Metz, 2003). Concerns with regard to disability access and shared transport schemes might range from a complete lack of accessibility in relation to some car or bike sharing schemes because the vehicles themselves are unsuitable, to barriers imposed by the way in which schemes are operated.

Physical disabilities can restrict the ability of some individuals to drive or cycle and, although adaptable vehicles may mitigate this, it is perhaps unrealistic to assume that vehicle design will be versatile enough for all potential user needs. However, vehicle design can be inclusive as possible. For example, shared bicycles can be sturdy, have adjustable-height seats and typically have three gears, making them easy to use (Midgley, 2011). There are increasing numbers of e-bike sharing schemes, removing some individual and built environment physical barriers to access. However, there needs to be wider debate about the extent to which such schemes should or can be designed to cater for all, for example, widening provision by offering a range of bicycles such as tricycles, e-bikes and children's bicycles or children's seats.

The discussion above relates mainly to medically diagnosed physical disability, which may lead to specific mobility requirements. Access to car and bike share schemes can also be restricted by other requirements: there are often age restrictions, excluding those below or above certain ages relating to car clubs. However, with regard to bicycle sharing in particular, physical ability is also a consideration. Concerns with physical health and fitness, both actual and perceived, may be a barrier to some people using these schemes. It might be possible to address this through marketing, to normalise the image of cycling (Goodman et al., 2014) or through training schemes such as 'bikeability' (Johnson \& Margolis, 2013). However, to be truly inclusive, mar- keting and training must go alongside re-design of the built environment, including appropriate and wellmaintained cycle infrastructure.

\subsection{Safety \& Security}

Safety and security can be barriers to the use of certain modes of transport. For shared bicycle and car schemes there are issues of both actual and perceived safety, relating to the location of the stations, which may determine whether they are deemed safe to use. Furthermore, there are temporal considerations, which may make a location, for practical purposes, inaccessible at different times throughout the day. It is recommended that stations are both well lit and under surveillance (Midgley, 2011) .

In addition to the static location of facilities, safety concerns related to infrastructure and the wider built environment can act as a barrier to participation in cycling (Saelens, Sallis, \& Frank, 2003) as well as having a role to play in driver safety (Ewing \& Dumbaugh, 2009; Ewing, Hamidi, \& Grace, 2014), although we are not aware of any evidence as to whether road design acts as a deterrent to driving. Furthermore, infrastructure may have differential benefits or adverse impacts on different groups, leading to inequality in access and highlighting a need for inclusive design of the built environment. Finally, helmets are often perceived necessary for safety. These can be provided under some bicycle sharing schemes, usually in countries with compulsory helmet laws. In other instances the lack of a helmet may be a perceived barrier to using bicycle hire schemes.

\subsection{Information}

Awareness of shared transport schemes and understanding of how they operate may limit participation for individuals. There is evidence that private car owners have difficulty grasping the total cost of car ownership (Turrentine \& Kurani, 2007) and so may not appreciated the cost-saving potential of car share. As noted previously, information about share schemes is usually provided online, which can be an exclusionary medium for those without internet skills or access. Furthermore, consideration should be given to who is the target audience of information campaigns. Given public investment, there should be consideration and targeting of groups to ensure inclusivity; however, this many not be a high priority from a commercial perspective.

\subsection{Provision of Services}

Bicycle share stations and car club parking spaces are unlikely to be evenly spread across the city they serve and will thus necessarily favour some population groups more than others. It is therefore important to consider whether the spatial patterning of provision ex- 
cludes some groups from accessing these modes, as a factor which may explain the inequalities in usage patterns identified by others (Ogilvie \& Goodman, 2012).

The location of destinations or geographical provision of services is an important component of accessibility to destinations and, as such, the component most usually measured by accessibility metrics. In the case study following, we use $400 \mathrm{~m}$ as a walk distance to a bicycle or car. Of necessity, we consider the bicycle stations and car club parking spaces as destinations relative to the characteristics of the residential population; in reality these modes may form part of multi-modal journeys. Home, therefore, may not necessarily be the location from which we should be considering accessibility. However, in the absence of more detailed journey information we use this as a starting point.

\subsection{Journey Time}

Journey time is one of the most studied aspects of accessibility (Curl, Nelson, \& Anable, 2013). It might also be important to consider how provision of shared transport modes contributes more widely to city level accessibility to destinations by making some destinations more accessible in terms of journey time to those without a private vehicle.

\subsection{Travel Horizons}

Travel horizons constitute another important aspect of accessibility, especially in relation to inclusion. Perceived accessibility may differ to that measured by any metric because individuals do not know or do not feel comfortable travelling to certain areas. Lack of awareness of transport options might be related to information or feeling uncomfortable related to safety, as previously discussed. Although shared transport modes have the potential to expand travel horizons, they may also exclude some by being located in destinations outwith their travel horizons.

\subsection{Summary}

Although each scheme will be different, we have outlined ways in which shared transport schemes in general might be considered inclusive or exclusive. In some respects, share schemes can be seen to be inclusive, through promoting cycling, normalising cycling (Goodman et al., 2014), widening travel horizons or adding to transport mode choices for those without access to their own car or bicycle. However, in many respects they can also be considered exclusive, benefitting some more than others. We have outlined the main aspects of inclusivity that we consider to be important for shared transport modes. In the following section we take two aspects, provision of services and cost, and examine these in relation to a case study.

\section{Case Study: A Socio-Spatial Equity Analysis of Shared Transport Schemes in Glasgow}

\subsection{Introduction}

This section presents a case study of socio-spatial analysis of car club and shared bicycle locations in Glasgow, Scotland. Glasgow is a post-industrial West European city, with a population in the metropolitan area of just over 1.1 million and approaching 600,000 in Glasgow City (National Records of Scotland, 2015). Over four in ten Glaswegians (41\%) commute to work as a car driver or passenger, while smaller proportions use public transport $(30 \%)$ or walk (26\%), and only $1.6 \%$ cycle (Understanding Glasgow, 2015a). There are marked economic and health inequalities in Glasgow, with almost half of those within the city boundary living in the $20 \%$ of most deprived areas in the country (Understanding Glasgow, 2015b). Glasgow provides an interesting case study in that it was host to the 2014 Commonwealth Games, one of the world's most wellestablished multi-sport events. In support of a promised Games physical activity 'legacy', the city introduced a mass automated bicycle hire scheme, run by 'nextbike' in 2014. The city also has a car club franchise, which has recently changed from 'City Car Club' to 'Co-wheels' (Carplus, 2015b). However, 'City Car Club' has retained some operations in the city meaning there are now two schemes, 'Co-wheels' run under the City Council franchise and 'City Car Club' operating privately. At this stage, the authors have been unable to obtain information relating to the way in which locations of car spaces or bicycle share stations are determined or to the usage of the schemes. However, we hope to pursue this in the future.

In this case study, we assess how the locations of these cars and bicycles are distributed relative to the resident population. Existing evidence suggests inequalities in who uses bicycle sharing (Buck et al., 2013; Ogilvie \& Goodman, 2012; Pucher et al., 2011) and car sharing (Loose, 2010; Rabbitt \& Ghosh, 2013) schemes. We seek to address whether the physical location favours such demographic groups and therefore whether the schemes can be considered inclusive on the basis of their distribution across the city. Then we consider the pricing structure and whether this promotes inclusivity.

\subsection{Methods}

Distance to stations has been reported as a significant predictor of usage of car and bicycle share schemes (Daddio, 2012; Katzev, 2003). In a study by Daddio

\footnotetext{
${ }^{1}$ Since the research was undertaken City Car Club has changed to Enterprise Car Club. We refer to City Car Club as this was the name, and therefore locations and costs, which were applicable at the time of research.
} 
(2012), respondents took an average of 10.75 minutes to access a car sharing bay, $76 \%$ of users walked to the car station and $15 \%$ cycled. However, in other research, $400 \mathrm{~m}$ has been used as a threshold for walking to car share stations (Abraham, 1999; Celsor \& MillardBell, 2007). Loose suggests that a distance of $500 \mathrm{~m}$ is optimal, with usage of car share schemes falling appreciably at higher distances (Loose, 2010). While recognising that there is a need for more research into acceptable walk distances to bicycle stations, we elected to adopt the lower $400 \mathrm{~m}$ threshold for both analyses, given that a relatively dense urban environment means that there are likely to be alternative public transport options within the same distance.

The locations of the bicycle stations and car club car park spaces were manually geocoded in QGIS using the location information from the company websites (Nextbike, 2015a; Co-wheels, 2015a; City Car Club, 2015a). We then used the Network Analyst extension in ArcGIS to create $400 \mathrm{~m}$ service areas, using the ITN road and path network, around each station as an approximation of the distance people are willing to walk to connect to another mode of transport. The service area polygons were imported back into QGIS and overlaid with datazones, which are a small-area geography used for census data in Scotland. The proportion overlaps between our service areas and datazones were calculated using polygon to polygon matching. We calculated both the proportion of each datazone which fell into service areas, and the proportion of the total service areas covered by each datazone so that we could apportion population data to the buffer zones around stations. This overlap was then exported to Ex- cel and population calculations using census data were undertaken in Microsoft Excel.

For the majority of census groups, we report the proportion in each demographic category which can access a bicycle or car station within a $400 \mathrm{~m}$ walk, relative to the total citywide population of each group. We calculated the number of each group living within the overall area covered by the service areas and then divided this by the total population of that demographic group in the city. The example below illustrates this calculation process (Figure 1).

As with any geographic analysis, there are issues related to the modifiable area unit problem. We are restricted by datazone geography for census data and our approach in matching this to service areas assumes that populations are spread evenly across each datazone, when in reality the population as a whole or certain sub-groups may be clustered within datazones. Secondly, by comparing to the population of Glasgow we face the issue that comparing with other geographical areas, such as the city centre only, or the greater Glasgow travel to work area, would yield different results. However, we chose this comparison given the allocation of public money to such schemes across the City Council area, so wish to understand whether the benefits are evenly spread across the population.

In the following sections, we use census data to compare the demographic composition of people living within $400 \mathrm{~m}$ of car, bike or car and bike stations in Glasgow with the population of Glasgow City Council area as a whole. A schematic representation of the location of car club parking spaces and bicycles is given in Figure 2.

If a datazone contains 600 females, and 5\% of the surface area of the datazone overlaps with the service area then 30 females are assumed to live within the area accessible to a station. This is repeated for all datazones which overlap the surface area to calculate the total of each demographic group living within the $400 \mathrm{~m}$ buffer.

For continuous data, cars per household, cars per person and mean age we instead used the proportion of the service area covered by each datazone to weight the mean for each overlapping datazone according to the amount it 'contributes' to the total service area, based on surface area.

For example: If datazone 1 (mean age 57) accounts for $45 \%$ of the total service area and datazone 2 (mean age 65) accounts for $55 \%$ overall mean age for the service area is $(57 \times 0.45)+(65 \times 0.55)=61.4$.

Figure 1. Calculation Process for matching of census data to service areas.
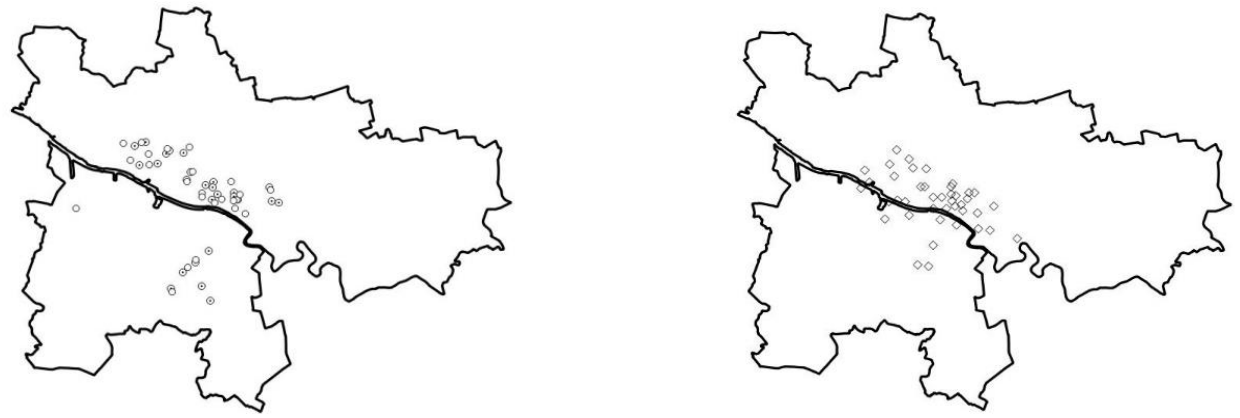

Figure 2. Location of car share (left) and bicycle share (right) schemes in Glasgow. 
As might be anticipated, there is a clustering around the city centre. This is more pronounced in the case of bicycle stations, while there is a greater spread of car clubs, particularly towards the heavily residential south side of the city.

\subsection{Glasgow City Population}

We open by presenting Glasgow City population characteristics believed to be relevant to transport inclusion and associated with cycling. These include gender, age, ethnicity, and socio-economic indicators such as housing tenure, car ownership, qualifications, employment status, as well as main mode of travel to work (Ricci, 2015, Table 1).

Table 1. Population characteristics of Glasgow. Source: Census 2011.

\begin{tabular}{lc}
\hline & Glasgow City Council Area \\
\hline Population & 593,862 \\
Households & 285,899 \\
Female & $52 \%$ \\
Male & $48 \%$ \\
Mean age & 38 \\
Age 0-15 & $4 \%$ \\
Age 16-29 & $24 \%$ \\
Age 30-45 & $22 \%$ \\
Age 45-65 & $24 \%$ \\
Age 65+ & $19 \%$ \\
white British & $83 \%$ \\
non white British & $17 \%$ \\
Owned & $46 \%$ \\
social rented & $37 \%$ \\
private rent & $15 \%$ \\
no car & $51 \%$ \\
at least one car & $49 \%$ \\
cars per person & 0.31 \\
car per hh & 0.64 \\
No Qualifications & $32 \%$ \\
Qualifications & $68 \%$ \\
Employed & $36 \%$ \\
Unemployed & $6 \%$ \\
PT & $28 \%$ \\
Car & $42 \%$ \\
Other & $20 \%$ \\
\hline
\end{tabular}

Table 2. Mean age and cars per person and household for those living within $400 \mathrm{~m}$ of shared car and bicycle schemes.

\begin{tabular}{llll}
\hline & $\begin{array}{l}\text { Bike } \\
\text { share }\end{array}$ & $\begin{array}{l}\text { Car } \\
\text { club }\end{array}$ & $\begin{array}{l}\text { Car club \& } \\
\text { bike share }\end{array}$ \\
\hline $\begin{array}{l}\text { Mean age } \\
\begin{array}{l}\text { Mean cars per } \\
\text { person }\end{array}\end{array}$ & 34 & 35 & 25 \\
$\begin{array}{l}\text { Mean cars per } \\
\text { household }\end{array}$ & 0.25 & 0.31 & 0.25 \\
\hline
\end{tabular}

The reporting of this data is by necessity simplistic: we recognise the limitations, for example, of using binary variables for ethnicity, employment and education level in that such an approach does not offer depth of understanding; nevertheless, it has the merit of clarity and ease of comparison. Furthermore, our methodology assumes that the population within each datazone is homogenous: this is not the case, biasing the results to some extent. However, datazone geographies are decided on the basis of areas which are relatively homogenous in terms of socio-demographic characteristics. That some characteristics are reported at the household level and some at the individual level also introduces difficulties in terms of interpretation. Additionally, while household car ownership may benefit all household members, it is not necessarily the case that all individuals within a household will have access to a car. We do not have scope to examine these intrahousehold dynamics here. However, we can nevertheless offer important insights into which groups of people may have lower access to car and bike sharing stations.

Across Glasgow City, $9 \%$ of the population (10\% of households) live within $400 \mathrm{~m}$ of a bike share station. $14 \%$ of the population ( $14 \%$ of households) live within $400 \mathrm{~m}$ of a car club space and $5 \%$ of the population $(5 \%$ of households) are within $400 \mathrm{~m}$ of both. The following sections show how access to car and bicycle sharing schemes varies by socio-demographic group. If all population groups had an equal level of access to car and bike stations, we would expect the proportion of the group which can access a station or parking bay to equal that of the population as a whole. Where there are differences, this can be considered an indication of socio-spatial inequality of access and an indication of potential exclusion of some groups with respect to accessing shared transport modes. Additionally, Table 2 shows the mean age, cars per person and cars per household of those who can access shared car and bicycle schemes within the specified walk radius.

\subsection{Access to Bicycle Sharing Stations}

There is some variation in access to bicycle station by gender, although the difference is slight (see Figure 3 ): $8 \%$ of females are within $400 \mathrm{~m}$ of a bike station compared with $10 \%$ of males. The $16-29$ year old population has greater access to bikes than other age groups. Perhaps surprisingly, higher percentages of the nonwhite British population fall within the specified walk radius. Furthermore, private renters have greater access than those who either own or are social renters. This can be considered a reflection of tenure patterns around the city centre and before suburban areas are reached.

Those households without car access have greater access to bicycle share stations (11\%), in comparison with a figure of $10 \%$ for households across the city. 


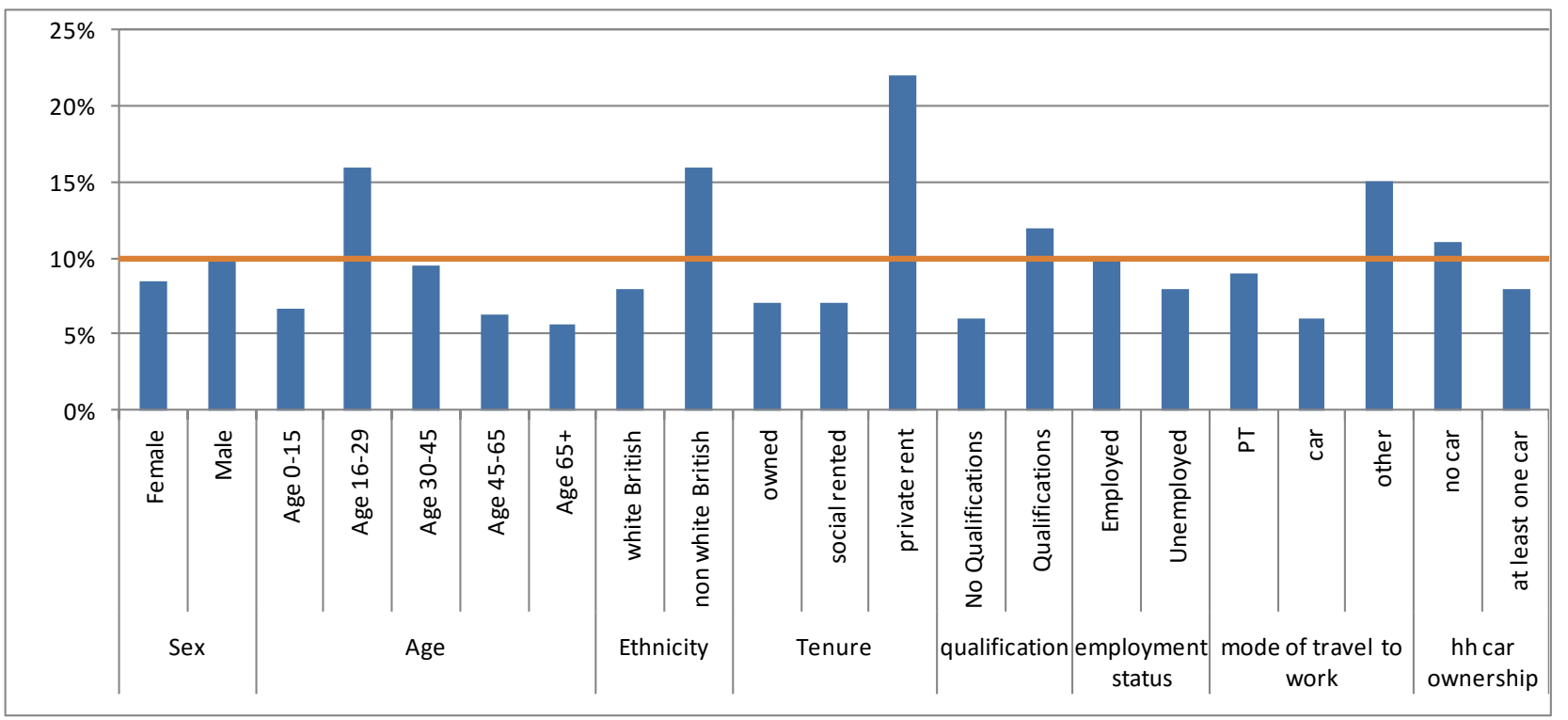

Figure 3. Proportion of the population who can access a bicycle sharing station within a $400 \mathrm{~m}$ walk.

That the number of cars per household is lower than the Glasgow average for households within $400 \mathrm{~m}$ of a bicycle station suggests bicycle share can be seen as inclusive, offering the option of another mode of transport for those without access to a car. However, given the clustering of stations in the city centre, it may also be that low levels of car ownership in the area reflect a lifestyle choice, rather than an issue with affordability. The latter possibility is strengthened when the demographic profile of those nearer stations is considered: people with qualifications and in employment also have higher rates of access to bicycle share, but in general are substantially more likely to be car owners than those without work or qualifications. This favours the possibility that, for at least some of this group, their education and employment might make car ownership an option which they have chosen not to exercise.

We analyse travel to work mode under three categories: public transport; car; and 'other', which would include walking or cycling. These data are from the 2011 Census, which was taken prior to the inception of bicycle share schemes in the city. Across Glasgow as a whole, an average of $9 \%$ of the population has access to a bicycle station within $400 \mathrm{~m}$. Of people who fall into the category of being relatively close to a bicycle share station, the proportion of public transport users is the same as the population average but considerably lower with respect to car users. For people who fell into the 'other' category at the 2011 Census, which would include those who walk or cycle to work, the proportion of people with ready access to bicycle rental is considerably higher. This indicates that the scheme appears to favour those who already live in areas where a high proportion of people cycle to work-a potentially fertile target market in terms of encouraging new users through social norms. Nevertheless, it also raises questions as to the ability of the schemes to achieve modal shift from car use.

\subsection{Access to Car Club Parking Bays}

Given the similarities in distribution of car and bicycle share stations, many of the patterns identified for bicycle sharing stations are similar for car club parking bays (see Figure 4). As might be anticipated, men have slightly better access than women. Similarly, when looking at age, people in the 16-29-year-old category have greater access than other age groups, although this is more evenly spread than for bicycle stations and, notably, a greater proportion of 30-45 year olds have access to cars than to bicycles.

As with the bicycle stations, the non-white British population have greater access, as well as there being considerably higher access among private renters than those who are either homeowners or social renters.

Access to car club cars is equivalent between car and non-car owning households. If car clubs were to be viewed as inclusive we might assume that access should be greater for non-car owning households, so that people without a private vehicle could benefit. However, household car ownership does not mean that all individuals have access to that vehicle and, for those within $400 \mathrm{~m}$ of car club bay, the mean figure for cars per household is lower than the Glasgow average, 0.60 compared to 0.64 (Table 1 and Table 2).

Similar to bicycle stations, those with at least a school level qualification and who are in employment have greater access to car club bays.

Of those who travel to work by a mode other than car or public transport, $20 \%$ can access a car club bay within $400 \mathrm{~m}$. Again, this raises the issue of environmental sustainability as, on this basis, car clubs may actually lead to higher car use by attracting people who do not currently drive. On the other hand, in contrast to bicycle sharing schemes, there is no difference in access 


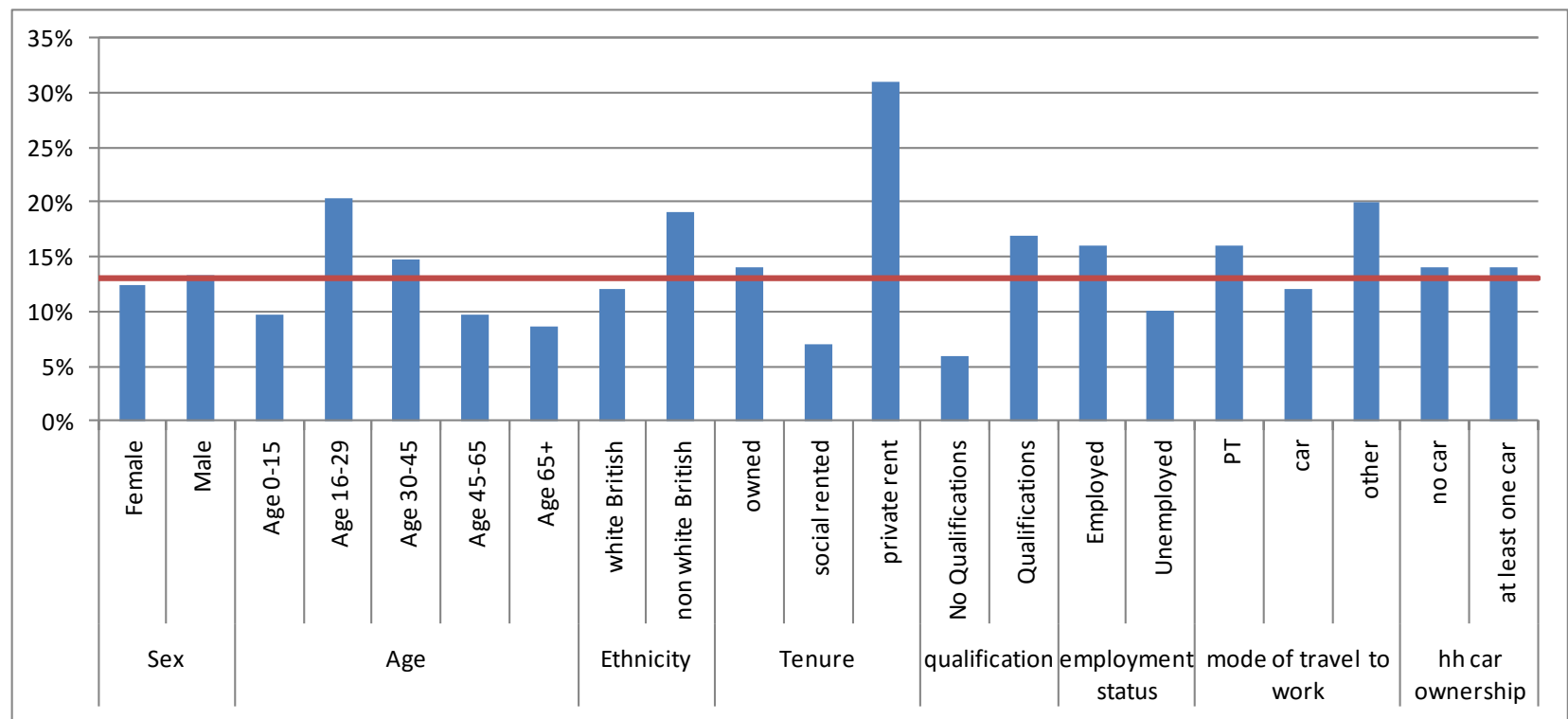

Figure 4. Proportion of the population who can access a car sharing bay within a $400 \mathrm{~m}$ walk.

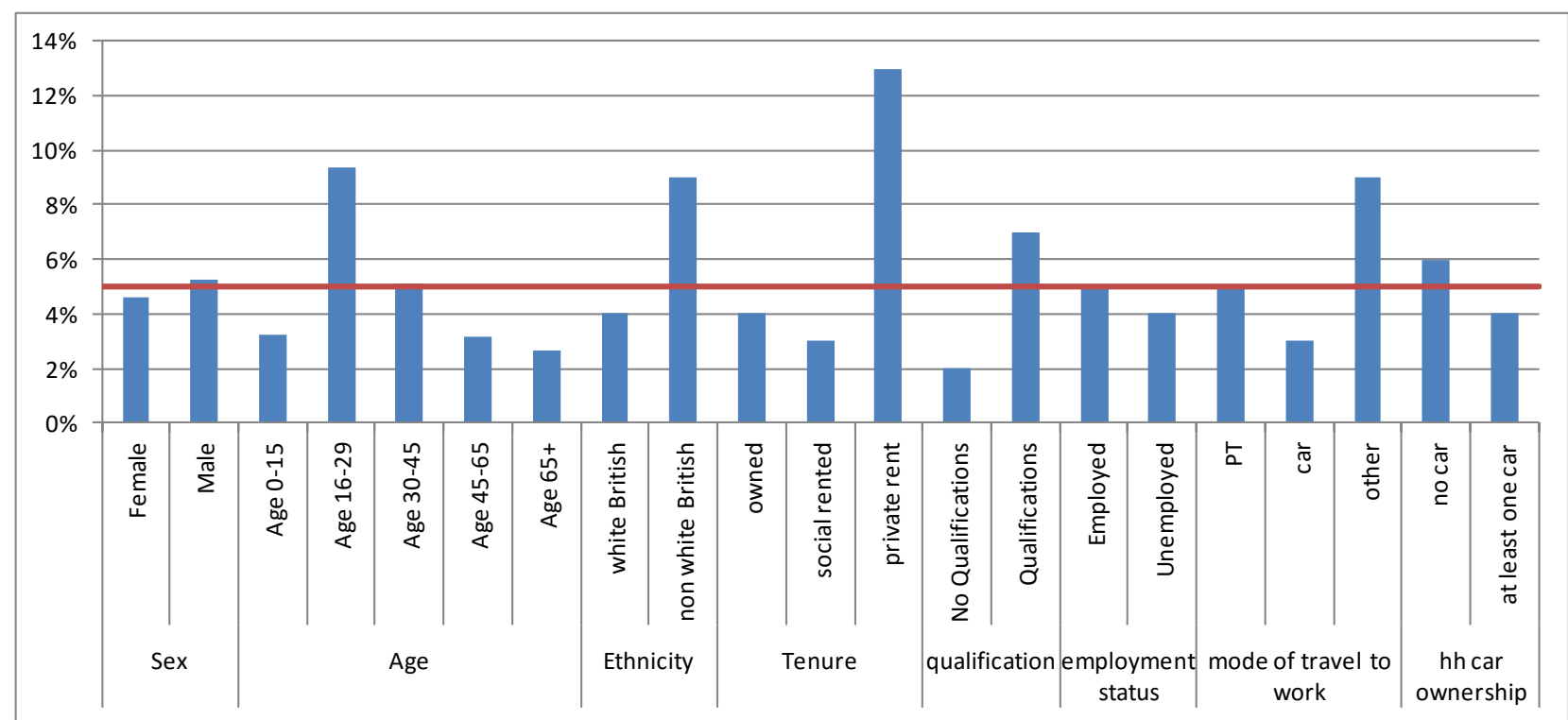

Figure 5. Proportion of the population who can access both bicycle and car share schemes within a 400m walk.

to car sharing bays between groups who do or do not have a car. The mean figure for cars per household and per person are both greater for people in areas where there are car parking bays than areas where bicycle share is available.

\subsection{Access to Both Bicycle and Car Club Stations}

Although fewer people (5\%) can access both car bays and bicycle stations than either car or bicycle stations individually, the socio-spatial patterning remains similar: people who are aged 16-29, non white British, private renting, with educational qualifications, in employment and not travelling to work by car or public transport or owning a car have greatest access (see Figure 5).

We suggest that these results are a reflection of the clustered nature of the bicycle and car stations in central locations, which by default means that some population groups will have better access. At this point it is important to remember that proximity to stations does not equate to usage, although it is an important explanatory factor (Katzev, 2003). Groups show to have greater access in this analysis can be considered comparable to those who we identified as users of such schemes in the literature review, insofar as there is a slight predominance of men and those in younger age groups, and in some form of employment, with qualifications. Although these are not necessarily particularly affluent areas, they are also not areas of high deprivation, in that people within the walk radius tend to rent privately or own their homes, rather than live in social housing. This would suggest that targeting stations and parking bays in certain areas may lead to usage, and 
therefore act as a policy mechanism for furthering transport inclusion. Furthermore, targeting at areas with existing poor accessibility and higher unemployment could be one means of promoting these schemes as inclusive modes of transport, especially given that access is poorer for the unemployed and those without qualifications.

From a commercial perspective therefore, the spatial location of both car and bicycle schemes might make sense: they are in locations likely to lead to higher usage of the schemes, highlighting the role of market forces. However, given the public investment we need to consider whether they can be considered socially inclusive. Additional to considering the economic dimensions of social inclusion, our research shows relatively large proportions of non-white British residents living close to share stations, and factors affecting usage for these populations are unknown.

We have assessed the spatial accessibility by demographic group to the fixed locations where car and bicycle sharing can be accessed. However, we have not considered the fact that vehicles may not always be available at these locations and whether a lack of alternative transport modes may be a hindrance to using or relying on such modes.

\subsection{Cost-Structure}

As discussed in Section 3, cost is also a key consideration when evaluating the inclusivity of shared transport schemes. In theory, such schemes have lower entry costs than upfront car or bicycle ownership and therefore potentially present a low-cost means of using either a car or bicycle. The pricing structures for bicycle sharing and car clubs in Glasgow are shown in Figures 6-8.

Bicycle sharing offers a membership or nonmembership option with slightly different usage rates. One of the car clubs charges an hourly or daily rate plus a mileage rate alongside a membership fee, whereas the other has a minimum monthly spend of $f 5$, and hourly or daily rate plus a mileage rate. The daily and hourly rates depend on the type and size of vehicle.

A single bus fare within the city costs $£ 2$ (approximately €2.55/ \$US2.90). This is likely to be more expensive than a bicycle hire for equivalent distance, but is substantially cheaper than a car club journey, although this is a broad comparison and will vary by journey and by time of day. Annual public transport tickets would provide savings, though we do not feel this is an appropriate comparison: if an individual were to purchase an annual public transport ticket, the assumption would be they would use it every day; using the shared car scheme every day would likely involve an unattractive (if not prohibitive) cost in comparison with actually buying a car. Comparing the daily fare provides a better reflection of the on-the-spot costs for casual users. Furthermore, paying annual or similar long-term advance charges for public transport travel tickets is also likely to be a problematic issue for those on lower incomes, even although daily fares may be more expensive on a per trip basis. The cost of an annual public transport 'zonecard', covering the city centre zones including the bicycle and car sharing schemes areas is £721 (approximately €910/ \$US1045). We therefore feel that this is a more realistic comparison. On this basis, the bus is more inclusive than car sharing in terms of walk-on fares and no upfront membership fees. However, bicycle sharing offers both options.

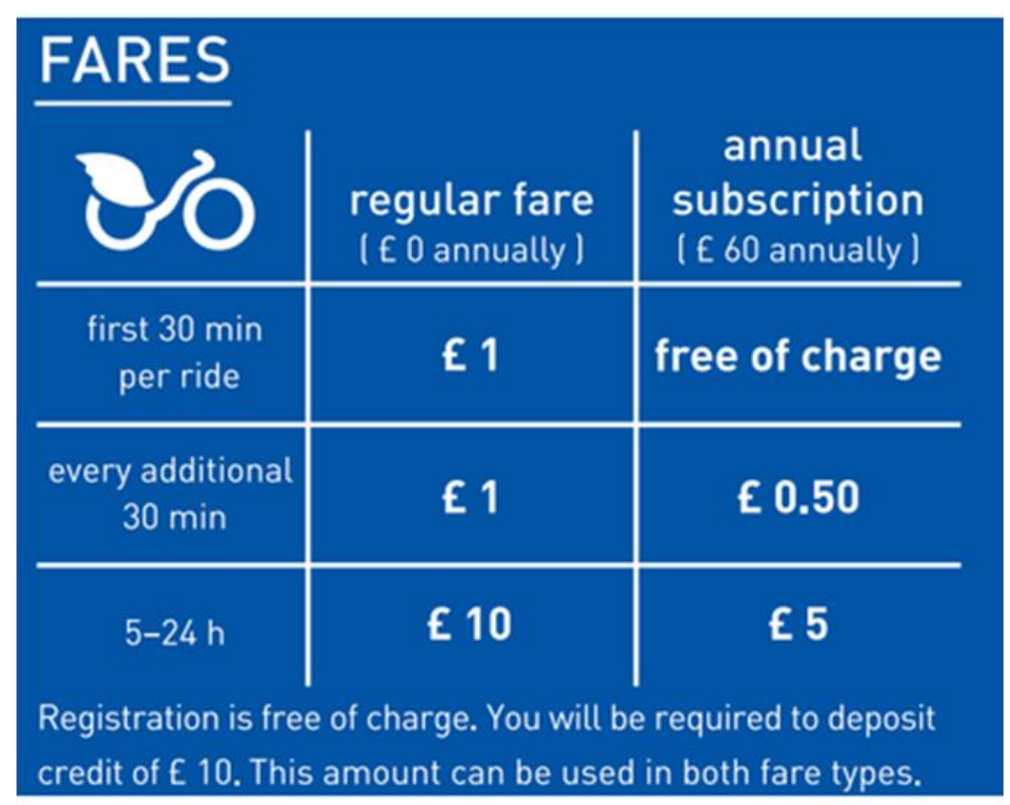

Figure 6. Nextbike cost structure. Source: Nextbike (2015b). 


\begin{tabular}{|c|c|c|c|}
\hline \multicolumn{2}{|c|}{ Vehicle type } & New hourly rate & New daily rate \\
\hline ब्वे & Small & $£ 3.95$ & $£ 25$ \\
\hline b-di & EV & $£ 3.20$ & $£ 20$ \\
\hline 60 & Medium & $£ 4.45$ & $£ 30$ \\
\hline 6 & Large & $£ 5.45$ & $£ 35$ \\
\hline 6 & 7 Seat & $£ 6.95$ & $£ 40$ \\
\hline $6-2$ & Vans & $£ 6.95$ & $£ 40$ \\
\hline
\end{tabular}

\section{Mileage rates:}

No mileage fee for electric and Prius Plug-in! | 13p/mile for small, medium, large \& 7 seat cars | $13 \mathrm{p} / \mathrm{mile}$ for vans The daily rate is the maximum you pay in any 24 hour period, plus the mileage charge when applicable. Please refer to our FAQ's for more information

\section{Sign up}

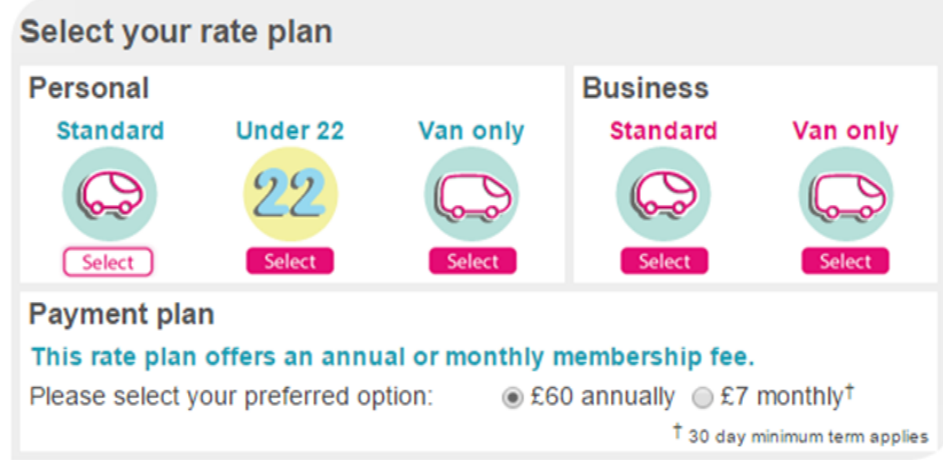

Figure 7. Cost structure for City Car Club. Source: City Car Club (2015b).

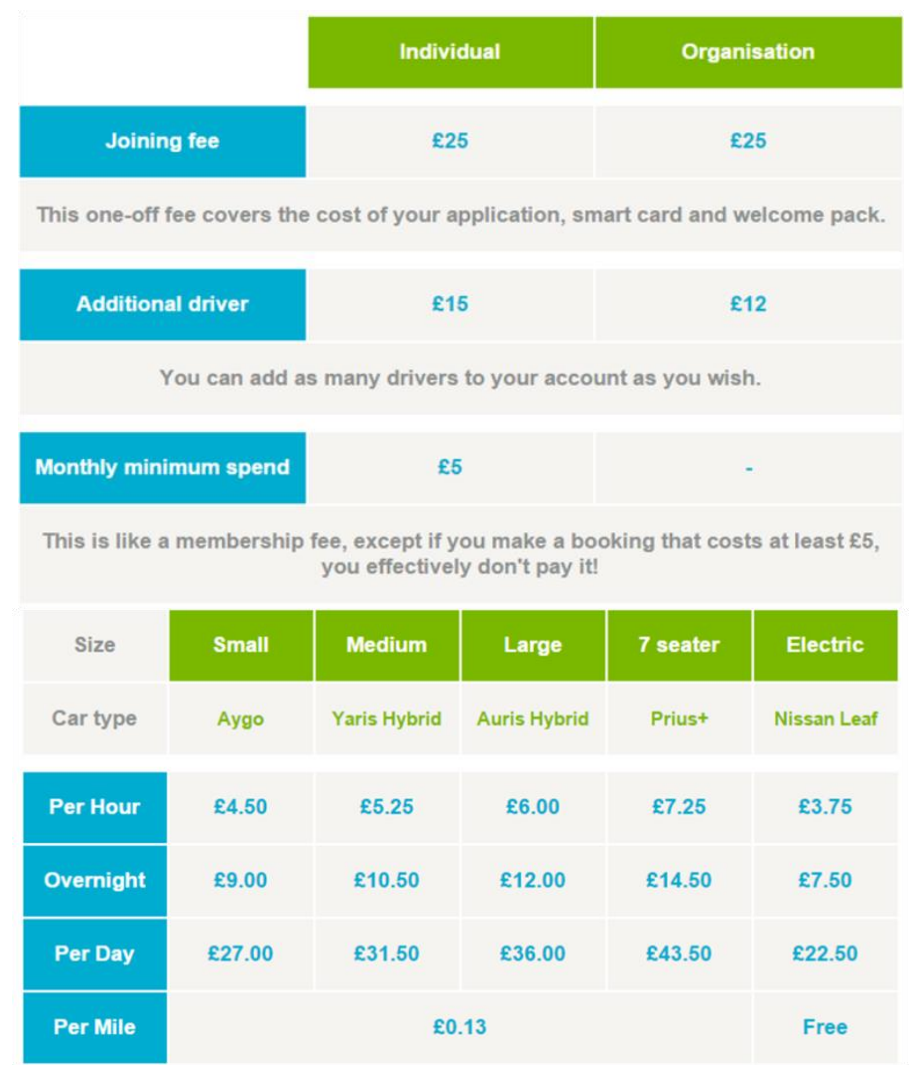

Figure 8. Cost structure for Co-wheels. Source: Co-wheels (2015b). 
The high entry costs, and relatively high usage costs for some of the car schemes may be a barrier to usage among those who do not have access to a vehicle. Furthermore the costs associated with driving lessons and a driving licence mean that this may not feasibly be seen as an inclusive mode of travel in terms of cost.

The costs associated with the bicycle scheme, on the other hand, are relatively low and, although the membership fee may be a deterrent to some, there is an option to avoid this. Anecdotally, we know that the bicycle share company is offering concessionary memberships through some employers (including some universities). This might limit its status as equitable in that all customers are not treated equally and those who may least need subsidised membership are being offered it, perhaps at a cost to other users, although we do not know this.

Both the car and bicycle schemes require individuals to be registered with the company and have a bank account. This excludes those without bank accounts, which is $12 \%$ of the population of Glasgow and $14 \%$ of those in the most deprived parts of Glasgow, compared with $7 \%$ in Scotland as a whole (Scottish Household Survey, 2015) therefore limiting the inclusivity of such schemes. In reality internet access may also be required.

\subsection{Summary}

On the basis of residential location, relatively low percentages of the population (10-15\%) have the potential to benefit from bicycle and car sharing stations across the city as a whole, raising questions as to the inclusivity of the schemes. However, it is important to note that, while proximity is important in predicting use, access does not equal usage. Not all those who can access a bicycle or car will use them, and others may use share vehicles to travel further or use employment-location stations as hubs. It is therefore important to study usage alongside the provision, comparing the demographics of users to the demographic of the areas where stations and parking bays are located. Although we believe this data to be available for our case study area, we have as yet been unable to access it.

We have presented an aggregate level socio-spatial analysis of car and bicycle sharing schemes in terms of proximity to access points in Glasgow. This gives a broad overview of how the spatial locations of these schemes are distributed across the population. More detailed, mixed methods analysis, including speaking with users of each mode, would allow firmer conclusions to be drawn.

\section{Conclusions}

There has been a recent surge of academic interest in shared transport modes. However, limited attention has been paid to how inclusive car and bicycle sharing schemes are, and to whether they might contribute to or address problems of transport-related social exclusion. In this preliminary work, we have applied learning from the fields of accessibility and equalities impact analysis to consider shared transport schemes. In doing so, we aim to problematise the easy assumption that shared transport will necessarily support social inclusion and mitigate transport disadvantage.

Although there is evidence to suggest that the benefits from bicycle sharing schemes are unevenly distributed across socio-demographic groups (Ricci, 2015), it is not clear whether this is because the schemes themselves are unevenly distributed, spatially and socially, thereby influencing who can access shared modes of transport and perpetuating inequality of access. In our case study, the demographic characteristics of those with access to both car and bicycle schemes are broadly similar, reflecting the central location of the stations. Car sharing schemes may be able to contribute to transport justice by improving car-based accessibility for those without access to a private vehicle. However, we found no evidence of differences in household car ownership for those with ready geographic access to the car sharing schemes. Furthermore, given the cost structure, it seems unlikely that car share will fulfil this role in the city. Overall, the location of the stations for both car and bicycle schemes makes sense from both commercial and mode-shift perspectives, appearing to favour those most likely to participate. Nevertheless, in this case, the market imperative means that share schemes are less likely to extend to those most at risk of transport-related social exclusion. This raises questions as to whether there are ongoing tensions between sustainability and social justice agendas. Achieving modal shift targets related to sustainability requires limiting travel, whereas social justice possibly requires increased travel among some socio-demographic groups. Overall, we would assess bicycle sharing schemes as being more inclusive, in that they involve fewer barriers to participation, particularly in relation to cost. However, there are serious limitations to inclusivity in relation to both actual and perceived safety concerns, which may be a major factor; for those less physically able, or parents struggling with shopping and children, bicycles may be less practical.

We intend that this paper will act as a catalyst setting a research agenda for more critical consideration of social inclusion, equity and justice related to emerging forms of transport. Given that some level of public investment is required to support shared transport schemes, issues of equality and inclusivity should not be ignored. Related to this, more consideration needs to be given to policy structure, governance and regulation and whether such schemes should be considered as quasi-public transport, which will increasingly be- 
come part of the urban transport system and can be used to meet transport policy goals related to sustainability and inclusion. We have discussed the inclusive nature of shared transport schemes in relation to a number of dimensions of what might constitute inclusive transport and then empirically examined spatial access and cost, but there is a need for more empirical work examining the other aspects such as physical access, information and safety and security. There is a need for more research to understand who and more importantly why people are (or are not) using shared transport schemes. In particular, this study highlights a need for mixed methods research, investigating the extent of share scheme usage by non-white British residents and exploring any barriers to use. While many studies have looked at the demographic of users, further comparison of this data with the demographic of the areas in which schemes are provided would reveal who is not using them and so make known more regarding the inclusive and equitable nature of delivery. Qualitative engagement with individuals across the socio-demographic spectrum would help illuminate the points we have raised here regarding how the schemes may or may not be considered inclusive modes of transport. Further work might be approached from two angles: firstly, whether the schemes are delivered in an inclusive manner; and secondly, whether shared modes might contribute more broadly to an inclusive transport system.

\section{Acknowledgments}

The authors gratefully recognize support from Dr Sharon Wright and the University of Glasgow Urban Studies Research Incentivisation Fund. We would also like to thank Professor Rowena Murray, whose encouragement and enthusiasm were an inspiration throughout this project.

\section{Conflict of Interests}

The authors declare no conflict of interests.

\section{References}

Abraham, J. (1999). Carsharing: A survey of preferences. World Transport Policy and Practice, 5(3), 189-200. Retrieved from http://trid.trb.org/view.aspx?id=747 392

Aldred, R. (2012). Governing transport from welfare state to hollow state: The case of cycling in the UK. Transport Policy, 23, 95-102. doi:http://doi.org/10. 1016/j.tranpol.2012.05.012

Appleyard, D. (1981). Liveable streets. Berkeley, CA: University of California Press.

Black, W. (2003). Transportation: A geographical analysis. London: The Guildford Press.
Buck, D., Buehler, R., Happ, P., Rawls, B., Chung, P., \& Borecki, N. (2013). Are bikeshare users different from regular cyclists? A first look at short-term users, annual members, and area cyclists in the Washington D.C. region. Transportation Research Record: Journal of the Transportation Research Board, 2387, 112 119. Retrieved from https://www.academia.edu/ 6076965/Are_Bikeshare_Users_Different_from_Reg ular_Cyclists_A_First_Look_at_Short-Term_Users_An nual_Members_and_Area_Cyclists_in_the_Washingt on_D.C._Region

Burton, E. (2001). The compact city and social justice. Paper presented at The Housing Studies Association Spring Conference University of York, UK.

Cairncross, F. (1997). The death of distance. London: Orion.

CarPlus. (2015a). Key achievements. CarPlus. Retrieved from http://www.carplus.org.uk/about/background-2

CarPlus (2015b) Glasgow: All change as Co-wheels launches 32 car fleet. Co-wheels Shared Mobility News. Retrieved from http://www.carplus.org.uk/arc hived_newsletter/shared-mobility-news-september2015

Celsor, C., \& Millard-Bell, A. (2007). Where does carsharing work?: Using geographic information systems to assess market potential. Transportation Research Record: Journal of the Transportation Research Board, 1992. Retrieved from http://trrjournalonline. trb.org/doi/abs/10.3141/1992-08

Church, A., Frost, M., \& Sullivan, K. (2000). Transport and social exclusion in London. Transport Policy, 7(3), 195-205. Retrieved from http://www.sciencedirect. com/science/article/B6VGG-41WSBDT-4/2/5362c77 2da815916234fff5f7b8c63f9

Clark, J., \& Kearns, A. (2014). The Glasgow 2014 games: Regeneration and physical activity legacy. Glasgow, UK: GoWell/ Glasgow Centre for Population Health. Retrieved from http://www.gowellonline.com/asset s/0000/3691/Prospective_Assessment_of_Active_Le gacy.pdf

City Car Club (2015a). Locations. City Car Club. Retrieved from https://www.citycarclub.co.uk/locations/glasgo w-car-hire

City Car Club (2015b). Car hire. City Car Club. Retrieved from https://www.citycarclub.co.uk/locations/glasgo w-car-hire

Co-wheels. (2015a) Locations. Co-wheelers. Retrieved from http://www.co-wheels.org.uk/locations

Co-wheels. (2015b). Pricing. Co-wheelers. Retrieved from http://www.co-wheels.org.uk/pricing

Curl, A., Nelson, J. D., \& Anable, J. (2013). Same question, different answer: A comparison of GIS-based journey time accessibility with self-reported measures from the national travel survey in England. Computers, Environment and Urban Systems, 49, 8697oi:http://doi.org/10.1016/j.compenvurbsys.2013.1 0.006 
Daddio, D. (2012). Maximizing bicycle sharing: An empirical analysis of capital bikeshare usage (Masters Dissertation). University of North Carolina at Chapel Hill, Norh Carolina, NC.

Daley, M., \& Rissel, C. 2011). Perspectives and images of cycling as a barrier or facilitator of cycling. Transport Policy. 18(1), 211-216

DeMaio, P., \& Meddin, R. (2015). The bike-sharing blog: International bike-share database. The bike-sharing blog Retrieved from http://bike-sharing.blogspot.co. uk/2015/07/international-bike-share-database.html

DETR. (2000). Social Exclusion and the Provision and Availability of Public Transport. London: DETR

Dowling, R., \& Kent, J. (2015). Practice and public-private partnerships in sustainable transport governance: The case of car sharing in Sydney, Australia. Transport Policy, 40, 58-64. doi:http://doi.org/10.101 6/j.tranpol.2015.02.007

Enoch, M. P., \& Taylor, J. (2006). A worldwide review of support mechanisms for car clubs. Transport Policy, 13(5), 434-443. doi:http://doi.org/10.1016/j.tranpol. 2006.04.001

Ewing, R., \& Dumbaugh, E. (2009). The built environment and traffic safety: A review of empirical evidence. Journal of Planning Literature, 23(4), 347-367. doi:http://doi.org/10.1177/0885412209335553

Ewing, R., Hamidi, S., \& Grace, J. B. (2014). Urban sprawl as a risk factor in motor vehicle crashes. Urban Studies, 53(2), 247-266. doi:http://doi.org/10.1177/0042 098014562331

Firnkorn, J., \& Müller, M. (2011). What will be the environmental effects of new free-floating car-sharing systems? The case of car2go in Ulm. Ecological Economics, 70(8), 1519-1528. doi:http://doi.org/10.101 6/j.ecolecon.2011.03.014

Fishman, E., Washington, S., \& Haworth, N. (2013). Bike share: A synthesis of the literature. Transport Reviews, 33(2), 148-165. Retrieved from http://www. tandfonline.com/doi/abs/10.1080/01441647.2013.7 75612

Goodman, A., Green, J., \& Woodcock, J. (2014). The role of bicycle sharing systems in normalising the image of cycling: An observational study of London cyclists. Journal of Transport \& Health, 1(1), 5-8. doi:http:// doi.org/10.1016/j.jth.2013.07.001

Goodwin, P. (1999). Transformation of transport policy in Great Britain. Transportation Research Part A: Policy and Practice, 33(7-8), 655-669. doi:http:// doi.org/10.1016/S0965-8564(99)00011-7

Goodwin, P., Hallet, S., Kenny, F., \& Stokes, G. (2012). Transport: The new realism. Oxford, UK: Transport studies Unit, Working Paper number 1062, prepared for Rees Jeffreys Road Fund. Retrieved from http://www.tsu.ox.ac.uk/pubs/1062-goodwin-hallett -kenny-stokes.pdf

Grant-Muller, S., \& Laird, J. (2006). Costs of congestion: A literature-based review of methodologies and analyt- ical approaches. Edinburgh, Scotland: Scottish Executive Social Research. Available from: http://www. gov.scot/resource/doc/153566/0041321.pdf

Hampshire, R., \& Gaites, C. (2011). Peer-to-peer carsharing. Transportation Research Record: Journal of the Transportation Research Board, 2217, 119-126. doi:http://doi.org/10.3141/2217-15

Heinen, E., van Wee, B., \& Maat, K. (2010). Commuting by bicycle: An overview of the literature. Transport Reviews, 30(1), 59-96. doi:http://doi.org/10.1080/ 01441640903187001

Hine, J., \& Mitchell, F. (2001). The role of transport on social exclusion in urban Scotland: Literature review. Edinburgh, Scotland: Scottish Executive Central Research Unit. Retrieved from http://www.gov.scot/ Resource/Doc/156591/0042062.pdf

Hine, J., \& Mitchell, F. (2003). Transport disadvantage and social exclusion: Exclusionary mechanisms in transport in urban Scotland. Aldershot, UK: Ashgate.

Johnson, R., \& Margolis, S. (2013). A review of the effectiveness of adult cycle training in Tower Hamlets, London. Transport Policy, 30, 254-261.doi:http:// doi.org/10.1016/j.tranpol.2013.09.005

Katzev, R. (2003). Car sharing: A new approach to urban transportation problems. Analyses of Social Issues and Public Policy, 3(1), 65-86. doi:http://doi.org/10. 1111/j.1530-2415.2003.00015.x

Kent, J. L., \& Dowling, R. (2013). Puncturing automobility? Carsharing practices. Journal of Transport Geography, 32, 86-92. doi:http://doi.org/10.1016/j.jtran geo.2013.08.014

Kenyon, S., Rafferty, J., \& Lyons, G. (2003). Social exclusion and transport in the UK: A role for virtual accessibility in the alleviation of mobility-related social exclusion? Journal of Social Policy, 32(3), 317-338.

Kim, K. (2015). Can carsharing meet the mobility needs for the low-income neighbourhoods? Lessons from carsharing usage patterns in New York City. Transportation Research Part A, 77, 249-260.

Kopp, J., Gerike, R., \& Axhausen, K. W. (2015). Do sharing people behave differently? An empirical evaluation of the distinctive mobility patterns of free-floating car-sharing members. Transportation, 42(3), 449-469. doi:http://doi.org/10.1007/s11116-015-9606-1

Kristensen, H. (1995). Social exclusion and spatial stress: The connections. In Beyond the Threshold: The Measurement and Analysis of Social Exclusion. Bristol: The Policy Press.

Lathia, N., Ahmed, S., \& Capra, L. (2012). Measuring the impact of opening the London shared bicycle scheme to casual users. Transportation Research Part C: Emerging Technologies, 22, 88-102. doi:http://doi. org/10.1016/j.trc.2011.12.004

Lee, P., \& Murie, A. (1999). Literature review of social exclusion. Cambridge, Massachusetts, USA: Polity Press

Loose, W. (2010). The state of European car-sharing (Final Report D 2.4 Work Package 2).Intelligent Energy 
Europe and Bundesverband CarSharing e. V. Retrieved from http://www.eltis.org/sites/eltis/files/ tool/the_state_of_carsharing_europe.pdf

Lucas, K. (2004). Locating transport as a social policy problem. In K. Lucas (Ed.), Running on empty: Transport, social exclusion and environmental justice (pp. 7-13). Bristol, UK: Policy Press.

Lucas, K., van Wee, B., \& Maat, K. (2015). A method to evaluate equitable accessibility: Combining ethical theories and accessibility-based approaches. Transportation, onlinefirst 3/3/2015 doi:http://doi.org/ 10.1007/s11116-015-9585-2

Marsden, G., Mullen, C., Bache, I., Bartle, I., \& Flinders, M. (2014). Carbon reduction and travel behaviour: discourses, disputes and contradictions in governance. Transport Policy, 35, 71-78e.

Metz, D. (2003). Transport policy for an ageing population. Transport Reviews, 23(4), 375-386. Retrieved from http://www.scopus.com/scopus/inward/record .url?eid=2-s2.0-0242369155\& partnerlD $=40$

Midgley, P. (2011). Bicycle-sharing schemes: Enhancing sustainable mobility in urban areas. United Nations Department of Economic and Social Affairs: Commission on Sustainable Development Background Paper No. 8 CSD19/2011/BP8. New York: United Nations Retrieved from http://www.un.org/esa/dsd/resour ces/res_pdfs/csd-19/Background-Paper8-P.MidgleyBicycle.pdf

Moore, J., Rodriguez, J., Tokuhiro, M., \& Wang, C. (2012). Where should the public sector invest in alternative modes of transport? A comparative study of car clubs and electric vehicles in London. London: The London School of Economic and Political Science in conjunction with Arup. Retrieved from http://car sharing.org/wp-content/uploads/2012/03/Final_Cap stone_Report_Arup.pdf

Muller, P. O. (2004). Transportation and urban form: Stages in the spatial evolution of the American metropolis. In S. Hanson \& G. Giuliano (Eds.), The geography of urban transportation (3rd ed.). London: The Guildford Press.

National Records of Scotland. (2015). Settlements and localities. Mid-year population estimates: age distribution errors. National Records of Scotland. Retrieved from http://www.nrscotland.gov.uk/statis tics-and-data/statistics/statistics-by-theme/populati on/population-estimates/special-area-population-est imates/settlements-and-localities

Nextbike. (2015a). Locations. Nextbike. Retrieved from http://www.nextbike.co.uk/en/locations

Nextbike. (2015b). Prices. Nextbike. Retrieved from http://www.nextbike.co.uk/en/prices

O’Brien, O., Cheshire, J., \& Batty, M. (2014). Mining bicycle sharing data for generating insights into sustainable transport systems. Journal of Transport Geography, 34,262-273.

Ogilvie, F., \& Goodman, A. (2012). Inequalities in usage of a public bicycle sharing scheme: Sociodemographic predictors of uptake and usage of the London (UK) cycle hire scheme. Preventive Medicine, 55(1), 40-45. doi:http://doi.org/10.1016/j.ypmed.20 12.05 .002

Parkes, S. D., Marsden, G., Shaheen, S. A., \& Cohen, A. P. (2013). Understanding the diffusion of public bikesharing systems: Evidence from Europe and North America. Journal of Transport Geography, 31, 94-103. doi:http://doi.org/10.1016/j.jtrangeo.2013.0 6.003

Preston, J., \& Rajé, F. (2007). Accessibility, mobility and transport-related social exclusion. Journal of Transport Geography, 15(3), 151-160.

Pucher, J., Buehler, R., \& Seinen, M. (2011). Bicycling renaissance in North America? An update and reappraisal of cycling trends and policies. Transportation Research Part A: Policy and Practice, 45(6), 451475. doi:http://doi.org/10.1016/j.tra.2011.03.001

Pucher, J., Dill, J., \& Handy, S. (2010). Infrastructure, programs, and policies to increase bicycling: An international review. Preventive Medicine, 50 Suppl 1, S106-25. doi:http://doi.org/10.1016/j.ypmed.2009.0 7.028

Pucher, J., \& LeFevre, C. (1996). The urban transport crisis in Europe and North America. Houndmills, UK: Macmillan.

Rabbitt, N., \& Ghosh, B. (2013). A study of feasibility and potential benefits of organised car sharing in Ireland. Transportation Research Part D: Transport and Environment, 25, 49-58. doi:http://doi.org/10.1016/j.trd. 2013.07.004

Reid, D. (1995). Sustainable development: An introductory guide. London: Earthscan.

Ricci, M. (2015). Bike sharing: A review of evidence on impacts and processes of implementation and operation. Research in Transportation and Business Management, 15, 28-38.

Rietveld, P., \& Daniel, V. (2004). Determinants of bicycle use: Do municipal policies matter? Transportation Research Part A: Policy and Practice, 38(7), 531-550. doi:http://doi.org/10.1016/j.tra.2004.05.003

Saelens, B. E., Sallis, J. F., \& Frank, L. D. (2003). Environmental correlates of walking and cycling: Findings from the transportation, urban design, and planning literatures. Annals of Behavioral Medicine: A Publication of the Society of Behavioral Medicine, 25(2), 8091. Retrieved from http://www.ncbi.nlm.nih.gov/ pubmed/12704009

Shaheen, S. A., Cohen, A. P., \& Martin, E. W. (2010). Carsharing parking policy: Review of North American practices and San Francisco, California, Bay Area case study. Transportation Research Record: Journal of the Transportation Research Board, 2187, 146-156. doi:10.3141/2187-19 Retrieved from http://tsrc.berk eley.edu/carsharingparking

Shaheen, S. A., Martin, E. W., Cohen, A. P., \& Finson, R. 
S. (2012). Public bike sharing in North America: Early operator and user understanding/research report. San José, California, USA: Mineta Transportation Institute. Retrieved from http://transweb.sjsu.edu/ project/1029.html

Sinclair, F., \& Sinclair, S. (2001). Access all areas: An assessment of social inclusion measures in Scottish local transport strategies. Edinburgh, Scotland: Centre for Research into Socially Inclusive Services. Retrieved from http://www.amazon.co.uk/Access-AllAreas-Assessment-Strategies-ebook/dp/BOOAVNUE70

Sloman, L. (2006) Car Sick: Solutions for our car addicted culture. Totnes, UK: Green Books.

Social Exclusion Unit. (2003). Making the connections: Final report on transport and social exclusion. London, UK: Social Exclusion Unit.

Stephany, A. (2015). The business of sharing: Making it in the new sharing economy. London: Palgrave Macmillan. Retrieved from http://www.palgrave.com/ page/detail/the-business-of-sharing-alexstephany/?sf1=barcode\&st1=9781137376176

Turner, J., \& Grieco, M. (2000). The impact of transport investment projects upon the inner city: A literature review. Time and Society, 9(1), 129-136.

Understanding Glasgow. (2015a). Transport overview. Understanding Glasgow. Retrieved from http:// www.understandingglasgow.com/indicators/transpo rt/overview

Understanding Glasgow. (2015b). Poverty overview. Understanding Glasgow. Retrieved from http://www.und erstandingglasgow.com/indicators/poverty/overview

Turrentine, T. S., \& Kurani, K. S. (2007). Car buyers and fuel economy? Energy Policy, 35(2), 1213-1223. doi:http://doi.org/10.1016/j.enpol.2006.03.005

Welch, T. F. (2013). Equity in transport: The distribution of transit access and connectivity among affordable housing units. Transport Policy, 30, 283-293. doi:http://doi.org/10.1016/j.tranpol.2013.09.020

\section{About the Authors}

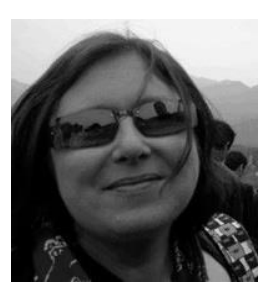

Julie Clark is an interdisciplinary, mixed methods researcher, who is primarily motivated by the potential of academic research to inform policy and alleviate critical social issues. She gained a doctorate in Urban Studies at the University of Glasgow for her mixed methods investigation of the relationships between social inclusion and car ownership, and has project managed the award winning, multi-strand, research project GoWell: Studying Change In Glasgow's East End, since it began in 2012.

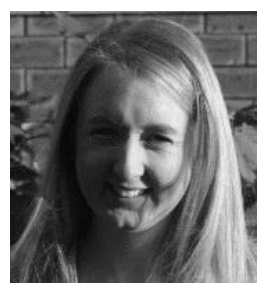

Angela Curl is a lecturer in health geography at the University of Canterbury, having previously worked in Urban Studies at the University of Glasgow and the OPENspace Research Centre at the University of Edinburgh. She completed her PhD (Geography) in 2013 at the University of Aberdeen, focussing on how perceptions of accessibility compare to objective measures. Angela's research interests are broadly in the area of transport and health with a particular focus on how the built environment contributes to travel behaviour, physical activity and health and wellbeing. 